\title{
A FORMAÇÃO DO PEDAGOGO PARA O ENSINO DE GEOGRAFIA NOS ANOS INICIAIS DO ENSINO FUNDAMENTAL
}

\author{
The formation of the Pedagogue for Geography education in years of elementary school
}

\author{
Vanice Schosser Sbardelotto* \\ Mafalda Nesi Francischett ** \\ * Doutoranda do PPG em Geografia da UNIOESTE - vanice.sbardelotto@unioeste.br. \\ ** Docente do PPG em Geografia da UNIOESTE - mafalda@wln.com.br.
}

Recebido em 02/08/2018. Aceito para publicação em 20/08/2018.

Versão online publicada em 03/09/2018 (http://seer.ufrgs.br/paraonde)

\begin{abstract}
Resumo:
0 artigo apresenta a pesquisa em desenvolvimento, no Programa de Pós-Graduação em Geografia, nível de Doutorado, na linha de Educação e ensino de Geografia, na Unioeste. Tem como foco principal a formação do pedagogo para o ensino de Geografia nos anos iniciais do Ensino Fundamental, no curso de Pedagogia. A problemática que emerge é "qual a formação do pedagogo em Geografia e como este contexto formativo possibilita conhecimentos para ensinar os conteúdos para as crianças pequenas?" A pesquisa se caracteriza como estudo de caso, pretende analisar a formação do pedagogo em Geografia. Os dados coletados serão analisados a partir das categorias formuladas ao longo da pesquisa, à luz da teoria crítica da educação.
\end{abstract}

Palavras-chave: Formação do pedagogo; ensino de Geografia; Anos Iniciais do Ensino Fundamental.

\begin{abstract}
:
The article presents the research in development, in the Program of Postgraduate in Geography, level of Doctoral, in the line of Education and teaching of Geography, in Unioeste. Its main focus is the formation of the pedagogue, in the course of Pedagogy, for the teaching of Geography in the initial years of Elementary Education, The problem that emerges is "what is the formation of the pedagogue in Geography and how does this formative context provide knowledge to teach the contents to the young children?" The research is characterized as a case study, intends to analyze the formation of the pedagogue in Geography. The collected data will be analyzed from the categories formulated throughout the research, in light of the critical theory of education.
\end{abstract}

Key-words: Education of the pedagogue; Geography teaching; years of elementary school..

\section{A problemática e intenções de pesquisa}

Este artigo apresentar a pesquisa em desenvolvimento no Programa de Pós-Graduação em Geografia, linha de Educação e Ensino de Geografia, nível de doutorado, na Unioeste, Campus de Francisco Beltrão.

A pesquisa se situa no campo investigativo da formação do professor para o ensino dos conceitos geográficos para crianças, compreendido no processo da educação básica, nos anos iniciais, ainda embora esse processo formativo das crianças possa iniciar-se mesmo antes da criança entrar na educação escolarizada, por processos de educação não-formal. 0 foco desta pesquisa se orienta para a formação do professor para o ensino que se desenvolve na etapa inicial da educação básica. Pela organização delineada pelas políticas da educação brasileira, a formação do professor para esta etapa 
se faz em cursos de pedagogia. Logo, investigará a formação de professores, no cursos de Pedagogia para o ensino da Geografia nos anos iniciais do Ensino Fundamental.

A formação do Pedagogo segue aos dispositivos legais para a formação de professores para a educação básica, entre eles, as Diretrizes Curriculares Nacionais para Formação de Professores para a educação básica, Resolução do CNE N.02/2015 e a Diretriz para o Curso de Pedagogia, resolução do CNE n.01/2006, que estabelecem uma grande área de abrangência de atuação e, consequentemente, demanda para a formação inicial. Estas Diretrizes indicam que a formação do Pedagogo deve compreender a dimensão da educação infantil, anos iniciais do Ensino Fundamental, incluindo os componentes curriculares da educação básica, também as competências em relação a organização do trabalho pedagógico, gestão escolar, modalidades de educação de jovens e adultos, educação especial, indígena, quilombola, entre outras.

Essas exigências curriculares respondem a Lei de Diretrizes e Bases da Educação Nacional N.9394 de 1996 (LDB 9496/96) que define o curso de Pedagogia como formação preferencial para o exercício da docência na educação infantil e nos anos iniciais do Ensino Fundamental, considerando a especificidade da fase do desenvolvimento infantil, o processo de alfabetização, além de, a mesma lei, conservar a formação do pedagogo como especialista de diferentes áreas, como orientação, supervisão e administração escolar. 0 curso de Pedagogia contempla, para formar o professor para atuar nos anos iniciais do Ensino Fundamental, estudos referentes ao ensino em Língua Portuguesa e Alfabetização, Matemática, Ciências Naturais, Geografia, História, Artes e Educação Física, além de elementos próprios da organização do trabalho pedagógico.

Diante do que se espera do pedagogo como docente e articulador do trabalho pedagógico, os requisitos formativos, que se desdobram nos componentes curriculares são, com alguma dificuldade, alocados em quatro anos de formação, correspondendo a 3200 horas de curso. Em virtude do público que tem buscado o curso e também diante das dificuldades da carreira docente, que tem afastado os jovens do magistério, entende-se que não seria viável aumentar o tempo de integralização do curso de Pedagogia. Cada competência esperada do egresso demanda a inserção no projeto do curso de elementos curriculares destinados à sua consecução, o que exige tempos curriculares destinados aos fundamentos da educação, tempo para a discussão em torno da gestão e da organização do trabalho pedagógico, tempo para os elementos curriculares destinados a formação nas áreas específicas que deverão ser ensinadas pelo pedagogo nos anos iniciais do Ensino Fundamental. Estes elementos, associados às práticas de ensino, e outros debates, segundo Contreras (2012) podem levar a formação das profissionalidades necessárias à ação docente, que superam assim, o domínio de conhecimentos técnicos ou específicos de cada área do conhecimento.

Esta problemática, do processo formativo no curso de Pedagogia, de acordo com Saviani (2012) tem acompanhado a Pedagogia nos últimos trinta anos, a saber, o debate sobre a premência na formação do "domínio dos conteúdos que serão objeto do processo educativo e o domínio das formas por meio das quais se realiza o referido processo" (SAVIANI, 2012, p. 132). Para ele, este debate apresenta uma problemática situada na dissociação entre forma e conteúdo, ensejando projetos formativos que ora defendem a ênfase em um ou outro polo.

Entende-se que desenvolver uma pesquisa sobre a formação do pedagogo para o ensino de Geografia nos anos iniciais deve considerar a problemática do próprio campo da Pedagogia, como bem expôs Libâneo no livro "Pedagogia e Pedagogos, para quê?", livro lançado em 1999 e que em 2009, estava na sua 11 $\underline{a}$ edição, demostrando a atualidade do debate. Nesta obra o autor apresenta um importante debate sobre os rumos do curso de Pedagogia e da própria Pedagogia a partir das definições da LDB de 1996, e na emergência das Diretrizes Curriculares do curso de Pedagogia que, acompanhando de forma mediatizada as discussões da ANFOPE - Associação Nacional pela Formação dos Profissionais da Educação, aponta a docência como central no processo formativo. Posiciona-se, esse autor, de forma contrária à defesa da ANFOPE, alegando que dessa forma se faz uma redução da Pedagogia à educação escolar. Questiona o autor "onde estão os especialistas de planejamento da educação, administração de sistemas, avaliação educacional e avaliação da aprendizagem, pesquisa pedagógica específica?" (LIBÂNEO, 2009, p. 11) 
Desta forma, há um ponto já pacificado quanto ao que deve formar o curso de Pedagogia? Saviani no livro "A Pedagogia no Brasil: história e teoria" de 2012, expõe que a história desse curso no Brasil tem uma trajetória de discussões que se inserem no âmbito dos objetivos educacionais existentes no país ao longo da sua história. De forma que sua construção, assim como de outros campos da ciência, ainda vem se consolidando. Ou seja, há uma discussão intensa sobre como formar o professor para os anos iniciais, se isso se faz no curso de Pedagogia e como isso se faz nesse curso. Nesse sentido, essa pesquisa se insere na perspectiva de analisar concretamente a formação do pedagogo para o ensino de Geografia, a partir da organização existente do curso de Pedagogia, particularmente o curso de Pedagogia da Unioeste de Francisco Beltrão, como unidade caso, com o objetivo de responder as questões: a formação existente se dirige à forma, ao conteúdo, ou superou essa aparente dissociação? Neste contexto que se apresenta, da organização dos cursos de Pedagogia, de acordo com a DCN de 2006, é possível assegurar o domínio de conhecimento para ensinar os conteúdos de Geografia? Quais seriam os caminhos formativos que melhor assegurem ao pedagogo as condições concretas do ensino dessa área nos anos iniciais do Ensino Fundamental?

De acordo com Saviani (2005) a atuação prática, exige do professor o domínio dos conhecimentos científicos convertidos em saberes escolares, e sua correlata forma de ensino. Esse processo é indissociável e compreende a gênese da ação do professor e pode-se inferir que a formação do professor poderia pautar-se pela dialética entre ensino e aprendizagem. Assim, para que se ensine Geografia é necessário conhecer esse campo científico e sua inter-relação com a sociedade, a tecnologia e a ciência de forma mais ampla, a produção e seleção dos conteúdos escolares, a sua forma própria de transmissão e além de considerar o estudante, suas etapas de aprendizagem e desenvolvimento.

Desta forma, a Geografia é um componente curricular do curso de Pedagogia, pois este é o responsável por seu ensino nos anos inicias. A título de exemplo, os egressos do curso de Pedagogia da Unioeste de Francisco Beltrão, formados pelo Projeto Político Pedagógico de 2008, tiveram, ao longo da sua formação, a disciplina - Fundamentos Teórico Metodológicos para o ensino de Geografia - de formação específica, com carga horária de $68 \mathrm{~h}$.

Embora existam algumas diferenças entre os projetos dos cursos de Pedagogia das diferentes instituições que o ofertam, há questões reflexivas importantes como: os componentes ministrados durante o curso de Pedagogia são eficazes e suficientes para que este profissional desempenhe o ensino de Geografia? Como o pedagogo aprende a Geografia que vai ensinar? Que Geografia ele ensina nas práticas de ensino do ao longo do curso? Que aspectos são fundamentais para o domínio do pedagogo para o ensino de Geografia?

Desta forma, a pesquisa em desenvolvimento tem o objetivo de investigar e analisar a formação do pedagogo para o ensino de Geografia nos anos iniciais do ensino fundamental. Para isso, se lança na tarefa de: a) compreender como o acadêmico de Pedagogia avalia os conteúdos de Geografia e sua importância, para sua prática nos anos iniciais do Ensino Fundamental; b) investigar e analisar como a formação para o ensino de Geografia contribui na formação do pedagogo para a docência interdisciplinar - na qual se inserem os conteúdos de Geografia - nos anos iniciais do Ensino Fundamental; c) investigar como o pedagogo aprende a ensinar Geografia, por meio do processo formativo desenvolvido no curso; d) evidenciar os conceitos fundamentais do campo disciplinar da Geografia necessários para o ensino nos anos iniciais, de forma a articular conteúdo e forma. Desta forma, pretende-se contribuir com a formação de professores para a educação básica, de forma particular, para os anos iniciais do Ensino Fundamental; adicionalmente, ao lançar luzes sobre essa especificidade, a formação do pedagogo para o ensino de Geografia.

\section{Formação de professores para a Educação Básica no Brasil e a formação para o ensino da Geografia nos anos iniciais.}

Compreender a formação dos professores para o ensino de Geografia nos anos iniciais exige 
compreender inicialmente os caminhos da formação de professores para a Educação Básica no Brasil. Saviani (2012) aponta que essa formação seguiu os interesses hegemônicos colocados para a escola, acompanhando essas tendências educacionais. Na atualidade essa formação é regulada pela Resolução do CNE no02/2015, que expressa um pensamento pedagógico preciso, voltado à formação prática dos professores. Essa inferência se deve ao fato de que essa Resolução assevera a tônica na prática de ensino como a centralidade do processo formativo, acentuando uma racionalidade prática para a formação de professores.

Nesse sentido, Martins (2010) já destacava que o legado da formação de professores dos últimos trinta anos tem sido uma inclinação à prática, em detrimento da formação integral humana do professor, de forma que este possa humanizar outros sujeitos. Ao discutir essa e outras questões, Callai (2016) evidenciou que as disciplinas de "Introdução aos Estudos Sociais" e "Metodologia dos Estudos Sociais", em cursos de Pedagogia nos quais trabalhou, acabavam dando mais ênfase à prática do que ao conhecimento efetivo da epistemologia, uma vez que "interessava mais aos alunos fazer atividades mais práticas para trabalhar depois em sala de aula, do tipo: como fazer uma maquete, como mostrar o relevo [...]", expõe que a problemática é presente, o que exige dos educadores, pesquisas engajadas com a preocupação de apontar o percurso do processo formativo que colabore com a melhor formação desses docentes. (CALLAI, 2016, p. 10).

Em relação a esta proposta para a formação de docentes, com ênfase na prática, Libâneo (2012) discute que esta reflete as expectativas com a formação das crianças nos anos iniciais do Ensino Fundamental. Há pelo menos três décadas as políticas curriculares para esse nível de ensino vem corroendo os conteúdos de ensino e em seu lugar, enfatizando a formação de competências e habilidades, vide Parâmetros Curriculares Nacionais de 1997 e a atual Base Nacional Comum Curricular. Este objetivo que se hegemonizou no Brasil explicita a manutenção de uma escola do conhecimento para os ricos e uma escola para o acolhimento social, destinada aos pobres, com ênfase nas aprendizagens mínimas, para a formação da autonomia e cidadania, entendida, neste contexto, como a inserção no mercado de consumo e de trabalho. Esta proposta, de acordo com o autor, deriva dos acordos da Conferência de Educação para Todos, ocorrida na Tailândia em 1990 e tem como finalidade, apontar os objetivos da educação escolar para os países pobres.

Este consenso, aliado a precariedade das escolas públicas brasileiras produziu uma circularidade nos anos iniciais do Ensino Fundamental em torno do letramento e aprendizado dos números e operações matemáticas básicas. Assim, se percebe que a regulamentação da formação de professores acompanha esse movimento, apontado a centralidade da prática no processo formativo em detrimento de uma sólida formação a partir das teorias educacionais, assim como das áreas do conhecimento que devem ensinar. Questões como a compreensão do espaço, do tempo histórico, das relações humanas com a natureza para a produção da vida, vão gradativamente, perdendo espaço nos currículos dos anos iniciais, assim como a estética, a arte e a filosofia e passando, consequentemente, ao largo do processo de formação dos professores que vão atuar nesse nível.

Sacristán (2000) aponta que as inovações curriculares correspondem ao negociado socialmente, assim, o resultado curricular dos anos iniciais expressa a correlação de forças que disputam a implantação de distintos projetos formativos, que interfere diretamente na formação de professores.

A Geografia nos anos iniciais tem um papel fundamental de possibilitar às crianças a leitura de mundo, que pode ser feita a partir da leitura do espaço construído socialmente. Assim a "Geografia pode servir para pensar o espaço. [...] É pensar a partir da dimensão espacial, do espaço construído" (CALLAI, 2016, p. 10). Isso contribui para que a criança se perceba sujeito em seu tempo e espaço determinados e que as suas condições, do seu lugar, não tem determinações por ele mesmo. Reduzir o ensino de Geografia nos AIEF dificulta esse processo para as crianças, aponta Callai (2016). Desta forma, pode depreender-se que ao reduzir o espaço desse campo científico na formação das crianças, e consequentemente na formação do professor, tem por objetivo não fornecer as ferramentas teóricas que permitem a construção de conceitos abstratos para a leitura do mundo objetivo. Essa ausência ou simplificação da Geografia a elementos ilustrativos e mnemônicos, para Lacoste (2012) ilustram o que se traduziu como a Geografia dos professores. 
Há necessidade de uma "alfabetização espacial" nos anos iniciais com "noções básicas de localização, organização, representação e compreensão da estrutura do espaço elaborado dinamicamente pela sociedade". (CASTROGIOVANNI, 2012, p. 11). Ainda que o termo alfabetização se reporte a apropriação do alfabeto, mutatis mutandis, pode-se pensar em conhecimentos básicas e elementares que confiram às crianças conhecimentos objetivos para compreender, analisar e produzir o mundo em que vivem. Ou seja, preocupar-se com o espaço todo, na sua integralidade de relações. Nesse sentido, Callai (2005) destaca que há um conjunto conceitual próprio da Geografia que permite o desenvolvimento do pensamento espacial, e, ao adquiri-lo, a criança, operando por conceitos, tornase capaz de ler o mundo.

Sforni (2015), a partir da psicologia histórico-cultural de Vigostski, aponta que essa apropriação dos conceitos modifica as atividades das funções psíquicas e cria novos níveis de desenvolvimento. Esse processo ocorre pela mediação dos signos - que são artifícios criados pelo homem que potencializam suas capacidades. O desenvolvimento de funções psicológicas superiores está estreitamente ligado à escolarização, visto que são elas que permitem o pensamento por conceito. Estes conceitos, possíveis pela utilização de signos podem ser do tipo espontâneo e científico.

Os primeiros são resultantes da experiência direta, enquanto os segundos são assimilados com ajuda do professor, sujeito que domina o conhecimento. 0 desenvolvimento dos conceitos científicos apóia-se nos conceitos espontâneos e supera-os por incorporação. Desta forma, ao apropriar-se de conceitos mais elaborados, as crianças serão capazes não só de compreendê-los, como também serão capazes de compreender conceitos mais simples, ou cotidianos.

0 processo de educação formal escolarizado tem a função de promover a aprendizagem dos conceitos do tipo científico, e neste movimento, produzir no indivíduo singular o resultado da humanização, e pela via da aquisição dos produtos culturais. Ao apropriar-se deste legado, os sujeitos podem ascender a autonomia de pensamento e assim guiar sua ação do mundo a partir de novos referenciais. Para que isso ocorra, a atividade de ensino deve ser devidamente organizada e esse ensino é o papel da escola "porque a humanidade produziu um conhecimento e a escola existe para isso, para fazer esse conhecimento chegar até os alunos" (CALLAI, 2016, p. 17).

Desta forma, passa a ser um desafio metodológico integrar os conhecimentos específicos de cada área curricular nos anos iniciais e de formar professores para desenvolver essa tarefa. Como integrar o estudo do espaço, a leitura de mundo com a alfabetização? Como integrar esses estudos com as demais áreas do conhecimento sem sobreposição forçosa de disciplinas? Como ensinar a compreender-se e ser no mundo por meio dos conhecimentos científicos?

Alguns indicativos explicitam que "somente a história da sociedade mundial, aliada à sociedade local pode servir como fundamento da compreensão da realidade espacial e permitir a sua transformação a serviço da humanidade". (SANTOS, 2008, p.22). Isso indica que o sistema educacional e as formas metodológicas adotadas para o ensino devem se complexificar na medida em que a sociedade se desenvolve. Nesse sentido, há concordância com Leontiev (1978), seja na relevância da relação dos conteúdos de ensino com a compreensão da vida social, seja na formação ajustada dos professores a esse fim, quando o autor expõe que

Quanto mais progride a humanidade, mais rica é a prática sócio-histórica acumulada por ela, mais cresce o papel específico da educação e mais complexa é a sua tarefa. [...] Esta relação entre progresso histórico e o progresso da educação é tão estreita que se pode sem risco de errar julgar o nível geral do desenvolvimento histórico da sociedade pelo nível de desenvolvimento do seu sistema educativo e inversamente (LEONTIEV, 1978, p. 273).

A necessidade histórica de qualificar o processo educativo a fim de que as novas gerações acessem ao legado cultural humano, requer uma constante avaliação dos processos formativos dos professores, que, nas escolas assumem deliberadamente essa função. Investigar a formação do pedagogo se insere nesse movimento. 


\section{3. $\quad 0$ processo de pesquisa}

0 desenvolvimento da pesquisa em tela, referente à formação do pedagogo em Geografia dos anos iniciais do Ensino Fundamental, conta-se com o arcabouço metodológico do estudo de caso. Pois, considera-se que o estudo de caso "é um meio de organizar dados, preservando do objeto estudado seu caráter unitário. Considerando a unidade como um todo, incluindo o seu desenvolvimento [...]. A totalidade de qualquer objeto é uma construção mental". (VENTURA, 2007, p. 384). Os dados coletados servirão como base para análise a luz de fundamentos teóricos que permitam estabelecer nexos entre os dados e a realidade que se quer explicar.

Ao optar por esta metodologia de investigação pretende-se conhecer as ferramentas conceituais e procedimentais do método. Dessa forma, ao empreender um estudo de caso, faz-se necessário que se desenvolvam quatro etapas fundamentais: "a) delimitação da unidade-caso; b) coleta de dados; c) seleção, análise e interpretação dos dados; d) elaboração do relatório". (GIL, 1995, p. 58).

Desta forma, o curso de Pedagogia da Unioeste, campus Francisco Beltrão, constitui-se a unidadecaso que se quer investigar, no que se refere à formação para o ensino de Geografia nos anos iniciais do Ensino Fundamental, por se tratar de um curso de Pedagogia que atende a legislação em vigor.

Serão sujeitos da pesquisa: a) os docentes que ministraram a disciplina de Fundamentos Teóricometodológicos de Geografia, entre os anos de 2010 e 2017; b) os estudantes concluintes do ano de 2016, considerando que, no momento do início da pesquisa, estes formados oferecem ao pesquisador relevantes pistas para o curso da investigação; c) os acadêmicos matriculados na disciplina de Fundamentos Teórico Metodológicos do ensino de Geografia, no ano de 2017. Estes serão acompanhados ao longo do ano, em três momentos distintos: no início e no final da disciplina e após a realização do estágio de regência.

Será necessário empreender um estudo teórico que permita compreender a realidade investigada, particularmente em relação à formação de professores para os anos iniciais do Ensino Fundamental pós LDB 9394/96; o curso de Pedagogia e suas múltiplas facetas formativas; o ensino de Geografia e sua formação no curso de Pedagogia, entre outros aspectos.

Além da coleta de dados junto aos sujeitos - acadêmicos do quarto ano em 2017, que se dará por meio de formulários ao longo do processo formativo da disciplina de Fundamentos Teóricos e Metodológicos do Ensino de Geografia e do estágio de docência, também serão objeto de análise o PPP de 2007 do curso de Pedagogia, os planos de ensinos da disciplina de Fundamentos Teórico e Metodológicos do Ensino de Geografia, que foram desenvolvidos entre 2010 e 2017, com ênfase na análise dos objetivos, desdobramentos de conteúdos e referências bibliográficas.

Por meio deste conjunto de dados pretende-se apresentar um diagnóstico sobre a formação do pedagogo para o ensino em Geografia, cujo objetivo é de conhecer, caracterizar essa formação, para que se torne possível a sua análise, com vista a responder as questões colocadas: a formação se volta à forma, ao conteúdo ou é possível a superação da aparente dicotomia? O processo formativo do curso oferece aporte aos pedagogos para o ensino dos conceitos fundamentais de Geografia? Esta realidade será interrogada e analisada a partir de categorias do método materialista histórico e dialético.

\section{Formulando conclusões...}

Dado o processo inicial da pesquisa, ainda não há conclusões preliminares que possam ser apresentadas, no que se refere à análise dos dados coletados.

Entretanto, há a clareza de que investigar e analisar o processo formativo é imprescindível para a 
formulação da tese que expresse uma forma concreta de formação dos Pedagogos para o ensino de Geografia nos anos iniciais. O que se entende por "forma concreta" é a superação do que Saviani (2012, p. 134) aponta em relação aos cursos de educação que "reuniram os especialistas das formas abstraídas dos conteúdos". Ou seja, uma formação no curso de Pedagogia que supere a dissociação entre conteúdo e forma e que considere a dialética entre ensino e aprendizagem o ponto central para formação de professores.

\section{Referências}

BRASIL. Ministério da Educação. Base Nacional Comum Curricular. 2017. Disponivel em: http://basenacionalcomum.mec.gov.br/images/BNCC 20dez site.pdf. Acesso em: 01/02/2018.

BRASIL. Resolução CNE/CP 1/2006. Diretrizes Curriculares Nacionais para o Curso de Graduação em Pedagogia, licenciatura. D.O.U., Brasília, 16 de maio de 2006, Seção 1, p. 11.

BRASIL. Resolução CNE/CP no 02/2015, de 1o de julho de 2015. Define as Diretrizes Curriculares Nacionais para a formação inicial em nível superior (cursos de licenciatura, cursos de formação pedagógica para graduados e cursos de segunda licenciatura) e para a formação continuada. Brasília, Diário Oficial [da] República Federativa do Brasil, seção 1, n. 124, p. 8-12, 02 de julho de 2015.

CALLAI, H. C. $O$ ensino e a pesquisa da Geografia para os anos iniciais do Ensino Fundamental. Revista Brasileira de Educação em Geografia, Campinas, v. 6, n. 11, p. 06-20, jan./jun., 2016.

CASTROGIOVANNI, A. C. Apresentação e compreensão do espaço geográfico. IN. CASTROGIOVANNI, A. C., CALLAI, H. C., KAERCHER, N. A. (orgs) Ensino de Geografia: práticas e textualizações no cotidiano. Porto Alegre: Mediações, 2012.

CONTRERAS, José. A autonomia de professores. $2^{\text {a }}$ ed. São Paulo: Cortez, 2012

LACOSTE, Yves. A Geografia - isso serve, em primeiro lugar, para fazer a guerra. 19a ed. Campinas, SP: Papirus, 2012

BRASIL. Parâmetros Curriculares Nacionais. Brasília: MEC/SEF, 1997

SAVIANI, Dermeval. Pedagogia histórico-crítica: primeiras aproximações. Campinas, SP: Autores Associados, 2005.

A pedagogia no Brasil: história e teoria. 2 ed. Campinas, SP: Autores Associados, 2012.

SFORNI, M. Interação entre didática e teoria histórico-cultural. Educação e Realidade, Porto Alegre, v. 40, n. 2, p. 375 - 397, abr/jun, 2015.

UNIOESTE. Resolução nº 374/2007 - CEPE. Aprova alteração do Projeto Político Pedagógico do curso de Pedagogia do campus de Francisco Beltrão. 